Applied Remote Sensing

\title{
Check dam identification using multisource data and their effects on streamflow and sediment load in a Chinese Loess Plateau catchment
}

Peng Tian

Guangju Zhao

Xingmin $\mathrm{Mu}$

Fei Wang

Peng Gao

Zhijuan Mi 


\title{
Check dam identification using multisource data and their effects on streamflow and sediment load in a Chinese Loess Plateau catchment
}

\author{
Peng Tian, ${ }^{a}$ Guangju Zhao, ${ }^{\text {b,c }}$ Xingmin Mu, ,c, Fei Wang, \\ Peng Gao, ${ }^{\text {b,c }}$ and Zhijuan $\mathrm{Mi}^{\mathrm{d}}$ \\ ${ }^{a}$ Northwest A\&F University, College of Resources and Environment, Yangling 712100, \\ Shaanxi Province, China \\ borthwest A\&F University, Institute of Soil and Water Conservation, 26 Xinong Road, \\ Yangling 712100, Shaanxi Province, China \\ gjzhao@ms.iswc.ac.cn \\ ${ }^{\mathrm{c}}$ Chinese Academy of Sciences and Ministry of Water Resources, Institute of Soil and Water \\ Conservation, 26 Xinong Road, Yangling 712100, Shaanxi Province, China \\ ${ }^{\mathrm{d}}$ Northwest A\&F University, College of Water Resources and Architectural Engineering, \\ Yangling 712100, Shaanxi Province, China
}

\begin{abstract}
During the recent six decades, numerous check dams have been constructed for soil erosion control and agricultural production, and have become the key measure for soil and water conservation in the Loess Plateau. Obtaining check dam information is very important for soil erosion control and river basin management. This study utilizes remote-sensing images in conjunction with Google Earth images and field survey to derive the spatial distribution of the check dams in the Huangfuchuan catchment. Multisource data including topographic maps, Landsat images, and images from Google Earth are collected for check dam identification. The results are verified based on a field survey. The water surface area of the check dams derives from in situ measurement and images present good relationship with the high correlation coefficient of 0.96 . Furthermore, the area extent and number of check dams derived from the remote sensing images are similar to those from Google Earth images. Historically, an increase in the check dam number, controlled area, and storage capacity indicate their substantial trapping effects on streamflow and sediment load in the Huangfuchuan catchment. This study may be a good reference for proposing an efficient approach to identify the check dams and provide decision supports for soil and water conservation in the Loess Plateau. (C) The Authors. Published by SPIE under a Creative Commons Attribution 3.0 Unported License. Distribution or reproduction of this work in whole or in part requires full attribution of the original publication, including its DOI. [DOI: 10 .1117/1.JRS.7.073697]
\end{abstract}

Keywords: check dams; multisource data; storage capacity; streamflow; sediment load; Huangfuchuan watershed.

Paper 13092 received Mar. 24, 2013; revised manuscript received Aug. 17, 2013; accepted for publication Aug. 27, 2013; published online Sep. 24, 2013.

\section{Introduction}

Check dams are the most widely applied engineering structures for soil and water conservation in the erodible regions. In the gully-dominated regions, check dams have been widely constructed for retaining floodwater, intercepting soil sediment, improving gully slope stabilities, and increasing farmlands. At the beginning of construction, a water body similar to a small reservoir usually existed behind the check dam. Gradually, fertile cropland formed for grain production in the region, where a water body was filled by sediment deposition. ${ }^{1}$

Unlike reservoirs, check dams are not common around the world. It has only been reported that check dams were implemented for soil erosion control in some countries and regions, such as France, Italy, Spain, China, etc. ${ }^{2,3}$ The majority of research on check dams has been conducted to investigate their impacts on geomorphology, channel morphology, river bed stability, and 
Tian et al.: Check dam identification using multisource data and their effects on streamflow...

sediment yield through both field measurement and numerical simulation. It has been concluded that the check dams captured sediments and led to a decrease in the longitudinal gradient upstream, but accelerated downstream erosion because of the increased flow transport capacity and scour processes. ${ }^{1,4,5}$ Bombino et al. ${ }^{6}$ addressed statistically significant differences in channel form, sediment, and vegetation among the upper, the lower reaches, and the intermediate sections of check dams in Southern Italian catchment. A reducing rate of $77 \%$ sediment yield by check dams has been reported by Boix-Fayos et al. ${ }^{2}$ in the Rogativa catchment of SE Spain. Ran et al. $^{7}$ analyzed the coarse sediment retention by check dams in five typical catchments in the midstream of the Yellow River, and found that the average sediment reduction ratio could reach $60 \%$ when the check dams area accounted for more than $3 \%$ of the drainage area.

In Chinese Loess Plateau, check dams have attractive advantages because of unique environmental settings and regional food supply needs.$^{5,8,9}$ For $>400$ years, check dams have been constructed for soil erosion control and agricultural production improvement. The check dams have become one of the most effective strategies for soil erosion control in the Loess Plateau. Especially during the recent six decades, thousands of check dams have been constructed in the region. By 2005, >120,000 check dams have been built on the Loess Plateau over the past 50 years and approximately 21 billion $\mathrm{m}^{3}$ of sediments have been captured by these dams. ${ }^{10}$ Although considerable studies have been conducted as mentioned above, the locations, storage capacities, and outflow methods have not been inventoried and documented. Thus, further understanding the mechanisms on the hydrological effects of check dams was impossible.

Traditionally, check dams and their storage capacity are estimated by using the topographic maps according to the in situ hydrographic survey with an electronic planimeter. ${ }^{11}$ However, this approach is usually laborious, costly, and time consuming. Advances in remote sensing, geographic information systems, and computer technology have made satellite images convenient and less expensive for reservoir or dam measurement and monitoring. ${ }^{12,13}$ Remote-sensing images provide invaluable and timely information on spatial distribution, spectral and temporal attributes for reservoirs, and dam operation and management. ${ }^{14,15}$ However, research on check dam identification and quantitative estimation of storage capacities by means of remote-sensing images are very rare. ${ }^{16,17}$ The few studies available mainly focused on individual reservoirs or a rather small watershed and as a result, only some tentative applications have been reported. ${ }^{18}$

To better understand the potential effects of check dams on hydrological processes and sediment yield at catchment scale, an accurate estimation of the check dam distribution and their storage volume becomes very important and necessary. The objectives of this study, therefore, were:

1. to identify the check dams in a Loess Plateau catchment by making use of multisource data;

2. to quantify the actual storage capacity of the check dams through established empirical relationships; and

3. to analyze the impacts of check dams on streamflow and sediment load in combination with recently observed dataset.

\section{Study Area and Data}

\subsection{Study Area}

The study area, Huangfuchuan catchment, is one of the most severe soil erosion areas with the average annual sediment modulus higher than 17,000 ton $/ \mathrm{km}^{2}$ (1955 to 2000). The Huangfuchuan River is a first-order tributary of the midstream Yellow River, located in the wind-water erosion criss-cross region. The river originates from the eastern part of the Ordos Plateau, flows through the transitional zone of the Loess Plateau and Inner Mongolia grassland, and empties into the main stream of the Yellow River in Fugu County of Shaanxi Province (Fig. 1). The Huangfuchuan catchment covers an area of $3246 \mathrm{~km}^{2}$ consisting of two subtributaries: Nalin River and Changchuan River. The main stream of the Huangfuchuan River is $137 \mathrm{~km}$ long with an average channel slope of $2.7 \%$. The watershed is located in the transitional belt of warm temperate and mesothermal zones with the average 
Tian et al.: Check dam identification using multisource data and their effects on streamflow...

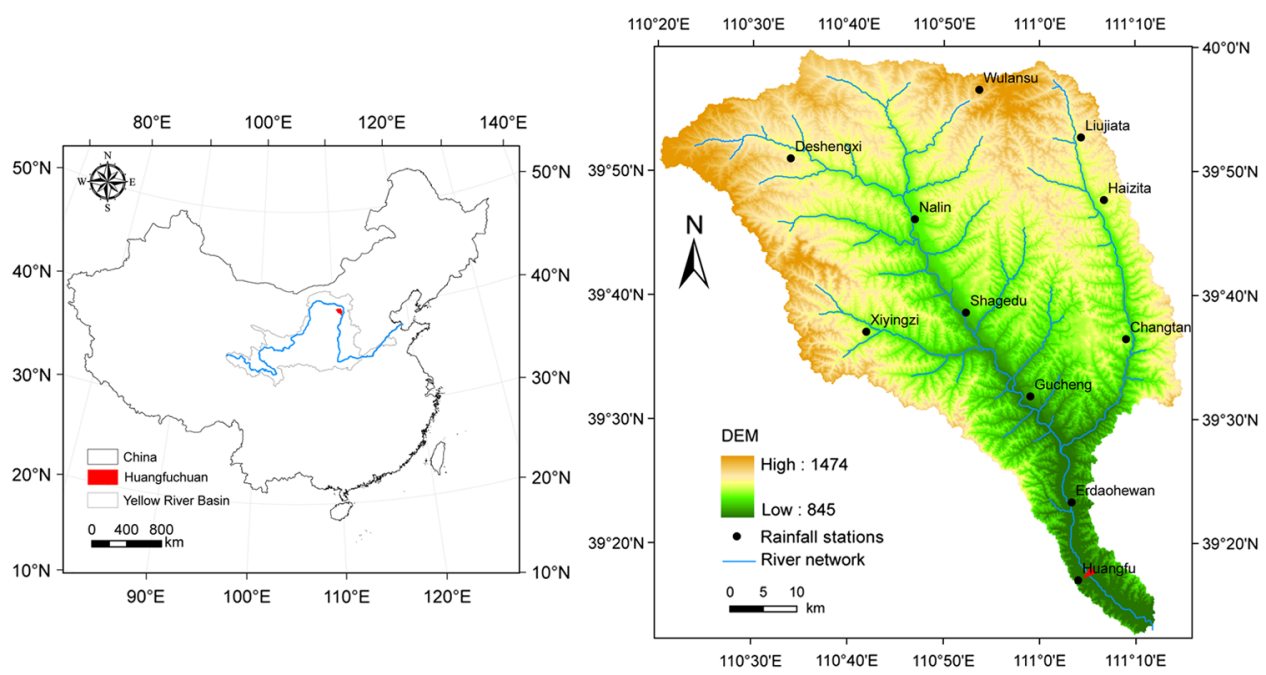

Fig. 1 Location of the study area and hydro-meteorological stations.

annual precipitation of about $380 \mathrm{~mm}$, influenced by southeast monsoon in summer, and characterized by semi-arid continental climate. ${ }^{19}$ Frequently occurring floods in July and August often cause tremendous soil erosion in the catchment. Average annual discharge and sediment load are $1.269 \times 10^{8} \mathrm{~m}^{3}$ and $0.408 \times 10^{8}$ ton, respectively, between 1955 and 2010, nearly $80 \%$ of which is concentrated in the rainy season from June to September.

The catchment can be described as "hilly and gully" landscape, and the land surface material is dominated by weathering sandstone, silty loess, and desert sand with coarser particles. According to the soil erosion type, the basin can be divided into three subregions: (1) loess hilly-gully region with an area of $918.3 \mathrm{~km}^{2}$, mainly located in the eastern and southwestern parts of the watershed; (2) the sandy loess hilly-gully region with an area of $546.1 \mathrm{~km}^{2}$, located between Nalin and Changchuan tributaries; and (3) the sandstone weathering hilly-gully region with an area of $1781.6 \mathrm{~km}^{2}$, located in the northwestern part of the catchment. Due to the extremely high gully density and soil erosion rates, check dams have become the dominant soil and water conservation measures in the Huangfuchuan catchment. By 2010, approximately $70 \%$ of the area in the Huangfuchuan watershed was controlled by check dams.

\subsection{Available Data}

The data used in this study were collected from topographic maps (1978), Landsat images (1990, 2007), and images acquired in 2010 from Google Earth. Table 1 lists all the available datasets and sources. In total, we collected 28 topographic maps with the resolution of 1:50,000 from Bureau of Survey and Mapping Shaanxi Province. The images were downloaded from the Landsat imagery database. ${ }^{20}$ The coverage of an individual Landsat TM image is $185 \times 185 \mathrm{~km}^{2}$. The resolution for bands 1 to 5 and 7 is $30 \mathrm{~m}$, while it is $120 \mathrm{~m}$ for band

Table 1 Summary of the processed maps and Landsat images.

\begin{tabular}{llccc}
\hline \hline Data & Resolution & Path/row & Date & Sources \\
\hline Topography map & $1: 50,000$ & & 1978 & $\begin{array}{c}\text { Bureau of Survey and Mapping } \\
\text { Shaanxi Province }\end{array}$ \\
\hline Landsat 5 & $30 \mathrm{~m}$ & 127 to 33 & $11 / 09 / 1989$ & http://earthexplorer.usgs.gov \\
Landsat 5 & $30 \mathrm{~m}$ & 127 to 32 & $13 / 08 / 1990$ & \\
Landsat 5 & $30 \mathrm{~m}$ & 127 to 32 & $10 / 09 / 2006$ & \\
Landsat 5 & $30 \mathrm{~m}$ & 127 to 33 & $25 / 09 / 2007$ & \\
Google Earth & $<15 \mathrm{~m}$ & & $23 / 06 / 2010$ & Google Earth images \\
\hline \hline
\end{tabular}


Tian et al.: Check dam identification using multisource data and their effects on streamflow...

6. Cloud free $(<1 \%$ cloud cover) images were selected. All the images were taken during the flood season, extending from August to September, to avoid various undesirable errors caused by adopting images taken in different seasons. Ran and $\mathrm{Lu}^{21}$ confirmed that the water surface area does not change significantly during the flood seasons, thus, the downloaded satellite images could capture the largest water surface area of the check dams.

\section{Methodology}

\subsection{Check Dam Identification from Multisource Data}

The topographic maps were geocoded to universal transverse mercator (UTM), zone 49N, using the WGS84 ellipsoid, and were used to delineate the check dams in ArcMap manually. Landsat images were subjected to atmospheric correction, radiometric calibration, and radiometric rectification procedures to facilitate comparability between dates. ${ }^{22}$ The Landsat images were georeferenced to 1:50,000 scale topographic maps using second-order polynomial transformation with the root mean square error of below 0.5 pixels $(<15 \mathrm{~m})$, and registration was verified visually by overlaying and swiping registered images. Due to the strong absorption and reflectance region in the infrared, visible red, and near-infrared bands (bands 7, 4, and 3) provided in the Landsat images, the combination of these bands was used to distinguish water bodies and land. The check dams or reservoirs were extracted by using the maximum likelihood supervised classification method in Erdas Imagine software. ${ }^{14,15}$ During the interpretation process, each 30-m pixel is classified as check dam (open water surface) or nondam area. Ponds and drainage network were distinguished from check dams through field survey. A database of the check dams (including volumes, built time, location, dyke height, remained/unfilled storage) were collected from Hydrology Bureau of the Yellow River Water Resources Commission. The volumes, built time, and dyke height were obtained through local census, and the remained storage for each check dams was calculated by combining bathymetric survey and storage curve analysis.

Currently, Google Earth has provided images of resolution of $<15 \mathrm{~m}$ covering the entire river basin. ${ }^{21}$ In addition, GPS field survey has similar accuracy of 10 to $20 \mathrm{~m}$ for ground truthing. ${ }^{11,15}$ Thus, we derived the spatial distribution and area extent of the check dams to verify the interpretation results of Landsat images. The images displayed by Google Earth were taken on June 23, 2010, coinciding with the capture time of the Landsat images. An update dataset for check dams in the Huangfuchuan catchment was obtained through images interpretation from Google Earth Pro.

Field survey was carried out in the beginning and end of the rainy season (May 2012 and October 2012). The outlines of the check dams were obtained with a Garmin 76 GPS instrument. The data stored on the GPS was converted into text formats which can be read by ArcCatalog. The points were connected together to form polygons. The surface areas and perimeters were then calculated.

To assess accuracy of the extracted check dam area from different data sources, both normalized difference area index (NDAI) and deviation area index (DAI) were applied. ${ }^{14,23}$ NDAI and DAI are defined as follows:

$$
\begin{gathered}
\mathrm{NDAI}=\left(\text { Area }_{\mathrm{gps}}-\text { Area }_{\mathrm{img}_{\mathrm{g}}}\right) /\left(\text { Area }_{\mathrm{gps}}-\text { Area }_{\mathrm{img}}\right), \\
\mathrm{DAI}=\left(\text { Area }_{\mathrm{gps}}-\text { Area }_{\mathrm{img}}\right) / \text { Area }_{\mathrm{gps}} .
\end{gathered}
$$

The NDAI value falls within the range between -1 and 1 with values close to 0 giving the best fit between the surface areas obtained from GPS and other sources, respectively. Values increasing to both extremes indicate increasing deviation between Area $a_{\mathrm{gps}}$ and Area $\mathrm{img}_{\mathrm{im}}$. Similarly, the DAI values also lie between -1 and 1 , with values close to 0 meaning the best linear fit, whereas values increasing to both extremes indicate larger deviation between Area $_{\mathrm{gps}}$ and Area $\mathrm{img}_{\mathrm{ig}}$. 


\subsection{Storage Capacity Estimation}

If reservoirs or check dams can be assumed to approximate the shape of a square pyramid diagonally cut in half, ${ }^{15,21,24}$ an empirical relationship between the storage capacity and its area can be expressed as

$$
V=a \times \text { Area }^{b},
$$

where $V$ is the check dams' storage capacity, Area is its water surface area, and $a$ and $b$ are the constants to be determined. If reservoirs are indeed exactly half pyramids, then $b=1.5$. When the slopes are more convex (rare), the constant $b$ is $>1.5$. In most cases of concave slopes, the value of $b$ is $<1.5$. Particularly, the parameters $a$ and $b$ are surprisingly constant within geomorphologically similar regions. ${ }^{15}$ However, it should be noted that the parameters may differ greatly in regions with geomorphologic heterogeneities. ${ }^{14,21,23}$ Thus, more attention should be paid when using the empirical relationship.

\section{Results}

\subsection{Correlation Between Field and Satellite Identified Check Dams}

Figure 2 presents the identified water surface area of the check dams from different types of dataset. In general, a good linear relationship was detected between the results from Landsat images and Google Earth images. As shown in Fig. 2(a), most points distributed close to $1: 1$ fit line with the relatively high correlation coefficient of 0.98 . Similarly, the water surface area from satellite images fitted well with field measurements [Fig. 2(b)]. However, it should be noted that some check dams built in the late 1950s and 1960s had been destroyed by flash floods or filled by deposited sediment. For example, the check dam in Fig. 3(a) was full of water in 1978 and dried up in 1990. A lifetime of about 10 years for small check dams to trap sediment efficiently was reported by $\mathrm{Xu}$ et al. ${ }^{5}$ Thus, the damaged or filled check dams may lead to some errors in the extraction of check dams from the images.

To further verify the water surface area derived from Landsat images, field surveys in 11 and 14 check dams were undertaken in May and October 2012, respectively. The NDAI and DAI were applied to detect the interpretation results. Table 2 compared the water surface area in check dams derived from images and field measurements. There is a very good linear fit between these two datasets. In most cases, we found that the water surface area from the Landsat images has overestimated the measurement values. Probably, the overestimation may result from the lower resolution of the Landsat images by which the surrounding nonwater features would have been misinterpreted as water. Furthermore, the results of supervised classification are largely dependent on the accuracy of the training data and their representative. In addition, the differences in water surface area may generate great discrepancies because of the uneven distributed
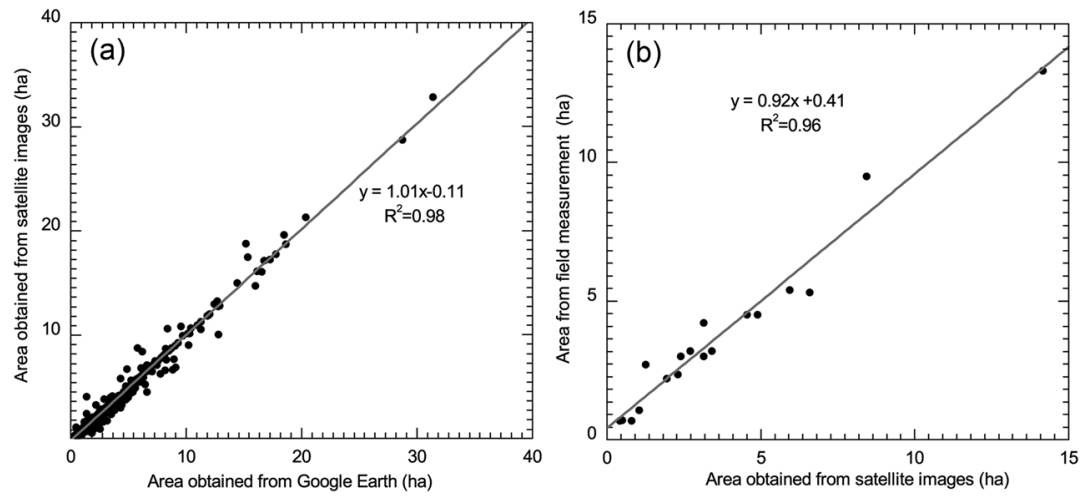

Fig. 2 Correlation of the estimated area from Landsat images, Google Earth, and field measurement. (a) Comparison the check dam area obtained from Landsat images and Google Earth, (b) comparison the check dam area derived from images and field survey. 


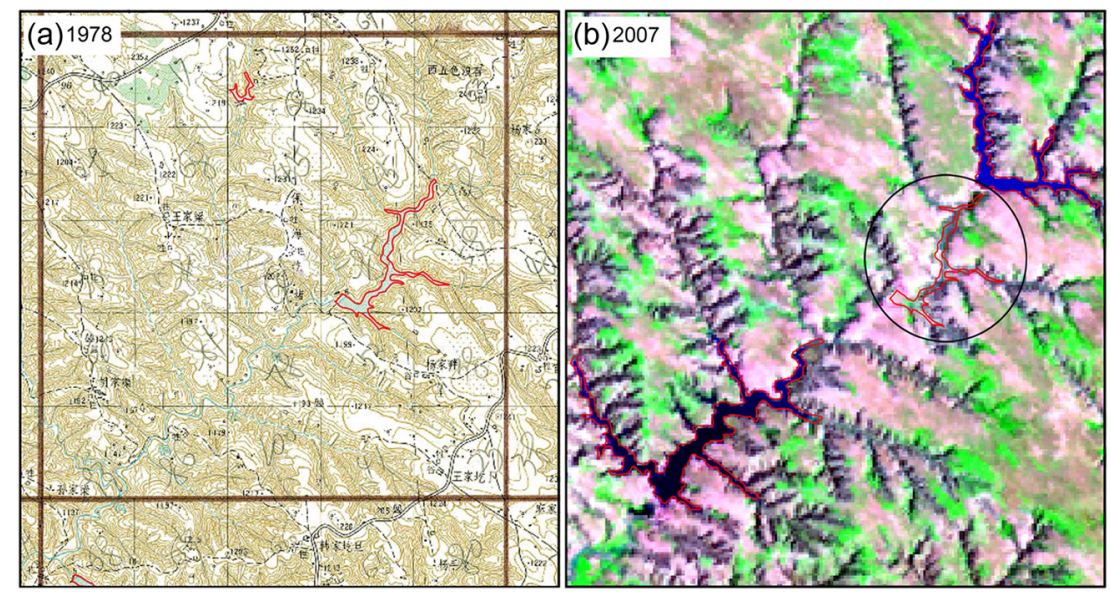

Fig. 3 Examples of check dam identification through topography map and images: (a) 1978 and (b) 2007.

precipitation in different seasons. For example, a minority of the check dams were dried up in May 2012, but there was a large area of water in October due to heavy storms in July.

\subsection{Storage Capacity Estimation in the Catchment}

In total, datasets of 74 check dams with spatial distribution, built date, storage capacities, and dike height were provided by the Yellow River Basin Committee. By representing various check dams with different storage capacities, these check dams were employed to develop the relationship between the water surface area and the storage capacity. As shown in Fig. 4, we investigated the relationship between the storage capacity and the water surface area as well as the damcontrolled area. The results indicate relatively good power relationship between the water surface area and the storage capacity, and logarithmic relationship between check dam controlled area and storage capacity. In contrast, Fig. 4(a) confirmed that the power equation represents a better relationship between check dam water surface area and storage capacity [Fig. 4(b)]. Thus, an empirical equation for calculating the check dams' storage is

$$
V=39.306 \times \text { Area }^{0.712}
$$

Equation (4) was applied to estimate the storage capacity of each check dam, and the total storage capacity was estimated by summing all individual check dams' storage together (Table 3). The total storage capacities in the Huangfuchuan catchment have increased from $2.65 \times 10^{8} \mathrm{~m}^{3}$ (1978) to $4.11 \times 10^{8} \mathrm{~m}^{3}$ (2010), and the average storage capacity for the check dams is nearly $7.25 \times 10^{5} \mathrm{~m}^{3}$. The estimated errors for storage capacities mainly result from the spatial heterogeneities in geometric shape and extracted water surface area. Ran and $\mathrm{Lu}^{21}$ addressed that each different geometric shape requires a unique parameterization to precisely calculate its storage capacity. In addition, the over- or underestimated water surface area may lead to misestimation of storage capacity for the check dams. However, compared with traditional field survey approach, the proposed method in this study was useful, efficient, and less expensive, and the estimation accuracy is satisfactory.

\subsection{Historical Dynamics of Check Dams}

Figure 5 shows historical dynamics of check dams derived from topographic maps (1978), Landsat images (1990 and 2007), and images of Google Earth in 2010. The results indicate that a general increase for the number of check dams can be clearly seen in the Huangfuchuan catchment. As well, the spatial distribution indicates that most of the check 
Tian et al.: Check dam identification using multisource data and their effects on streamflow...

Table 2 Comparison of water body area in check dams derived from images and field measurements.

\begin{tabular}{|c|c|c|c|c|c|c|c|c|}
\hline ID & Longitude & Latitude & Area $_{\mathrm{GPS}}$ (ha) & Area $_{\text {Sat }}$ (ha) & DAI (\%) & $\operatorname{NDAI}(\%)$ & Storage $\left(10^{4} \mathrm{~m}^{3}\right)$ & Built date \\
\hline 1 & 39.961 & 110.973 & 5.006 & 5.026 & -0.40 & -0.20 & 143.4 & 1993 \\
\hline 2 & 39.904 & 110.966 & 5.552 & 5.578 & -0.46 & -0.23 & 68.4 & 1987 \\
\hline 3 & 39.895 & 110.993 & 0.436 & 0.419 & 3.92 & 2.00 & 9.26 & 2004 \\
\hline 4 & 39.887 & 110.996 & 0.135 & 0.140 & -3.71 & -1.82 & 9.26 & 2004 \\
\hline 5 & 39.875 & 111.007 & 0.480 & 0.478 & 0.46 & 0.23 & 73.8 & 1987 \\
\hline 6 & 39.876 & 111.026 & 1.191 & 1.215 & -1.95 & -0.96 & 20.34 & 2004 \\
\hline 7 & 39.862 & 111.088 & 1.275 & 1.374 & -7.76 & -3.73 & 156.7 & 1989 \\
\hline 8 & 39.900 & 111.072 & 8.644 & 8.491 & 1.78 & 0.90 & 130.6 & 1993 \\
\hline 9 & 39.913 & 111.059 & 2.339 & 2.411 & -3.09 & -1.52 & 70 & 1988 \\
\hline 10 & 39.731 & 110.931 & 11.851 & 12.181 & -2.78 & -1.37 & 204.9 & 1990 \\
\hline 11 & 39.722 & 110.901 & 1.567 & 1.529 & 2.40 & 1.21 & 74 & 1997 \\
\hline 12 & 39.622 & 111.183 & 4.699 & 4.801 & -2.16 & -1.07 & 194.5 & 1992 \\
\hline 13 & 39.599 & 111.005 & 3.365 & 3.550 & -5.49 & -2.67 & 167.55 & 1977 \\
\hline 14 & 39.945 & 110.638 & 13.003 & 12.425 & 4.45 & 2.27 & 92.77 & 2005 \\
\hline 15 & 39.953 & 110.606 & 3.414 & 3.106 & 9.03 & 4.73 & 89.8 & 2005 \\
\hline 16 & 39.713 & 110.884 & 8.644 & 8.261 & 4.43 & 2.27 & 285 & 2001 \\
\hline 17 & 39.692 & 110.943 & 7.617 & 8.283 & -8.73 & -4.18 & 204.99 & 1989 \\
\hline 18 & 39.683 & 110.963 & 1.821 & 1.911 & -4.97 & -2.42 & 266 & 1990 \\
\hline 19 & 39.632 & 110.895 & 2.183 & 2.215 & -1.45 & -0.72 & 237.84 & 1993 \\
\hline 20 & 39.728 & 110.969 & 7.124 & 6.599 & 7.38 & 3.83 & 105.7 & 1994 \\
\hline 21 & 39.736 & 110.858 & 2.163 & 2.311 & -6.81 & -3.29 & 302.2 & 1990 \\
\hline 22 & 39.736 & 110.974 & 2.219 & 2.434 & -9.69 & -4.62 & 60.57 & 1992 \\
\hline 23 & 39.948 & 110.797 & 17.473 & 15.330 & 12.27 & 6.53 & 673.97 & 2001 \\
\hline 24 & 39.871 & 111.057 & 3.947 & 3.871 & 1.93 & 0.97 & 134.18 & 2005 \\
\hline 25 & 39.900 & 111.076 & 3.789 & 3.985 & -5.17 & -2.52 & 86.3 & 1987 \\
\hline
\end{tabular}

dams lie in the eastern part of the watershed. Taking the map of 2007, e.g., check dam density in the Wulan stream, Hujitu stream, and Tela stream show evident increasing trends. In 1978, there were only 16 check dams in the Wulan stream, while it had reached 118 in 2007 (Fig. 5).

Table 3 summarizes statistics of the check dams derived from multisource data in the Huangfuchuan catchment. By 1978, there were 390 check dams built in the Huangfuchuan catchment, with the water surface area of $10.76 \mathrm{~km}^{2}$. The dam-controlled area was $1226.56 \mathrm{~km}^{2}$, accounting for about one third of the whole catchment. By 2010, the number of check dams had reached 567, and the dam-controlled area was $2216.47 \mathrm{~km}^{2}$. This is consistent with the field survey data reported by the Hydrology Bureau of the Yellow River Water Resources Commission. Minor discrepancies were detected between Jiao et al. ${ }^{25}$ and our estimation. They addressed that 392 major check dams had been constructed until 1992 
Tian et al.: Check dam identification using multisource data and their effects on streamflow...
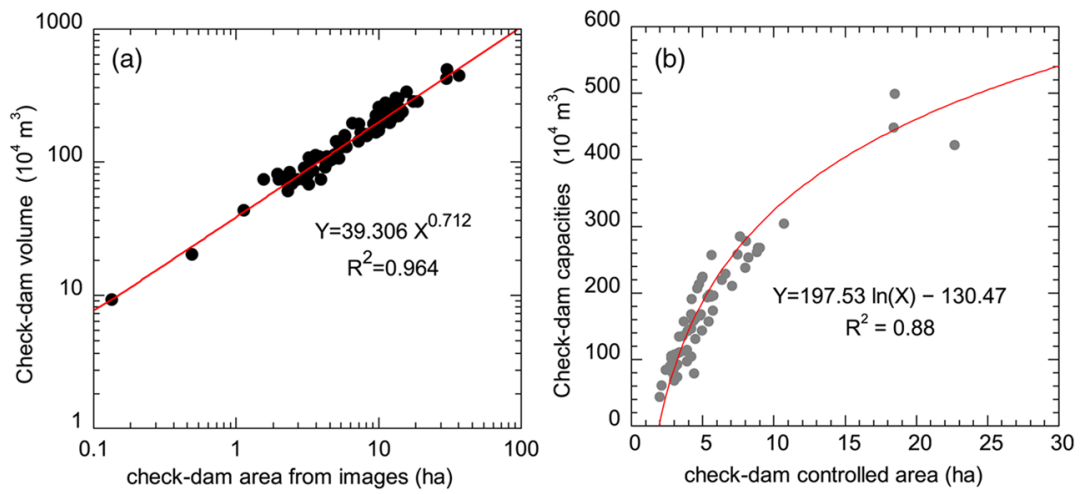

Fig. 4 Relationship between the estimated area and check dam storage. (a) power relation between dams' volume and area, (b) logarithm relation between dams' volume and controlled area.

Table 3 Statistics of check dams in the Huangfuchuan watershed from 1978 to 2010.

\begin{tabular}{lcccc}
\hline \hline Period & 1978 & 1990 & 2007 & 2010 \\
\hline Number of check dams & 390 & 445 & 504 & 567 \\
Water surface area $\left(\mathrm{km}^{2}\right)$ & 10.76 & 14.06 & 16.12 & 17.78 \\
Dams controlled area $\left(\mathrm{km}^{2}\right)$ & 1226.56 & 1531.61 & 1925.84 & 2216.47 \\
Total storage capacity $\left(10^{8} \mathrm{~m}^{3}\right)$ & 2.65 & 3.44 & 4.06 & 4.11 \\
\hline \hline
\end{tabular}

in the Huangfuchuan catchment, and approximately $1.07 \times 10^{8} \mathrm{~m}^{3}$ sediment had been trapped behind the check dams.

\section{Discussion}

\subsection{Potential Impacts of Check Dams on Streamflow and Sediment Load}

Figure 6 shows temporal trends of discharge and sediment load at Huangfu station. The abrupt changes were detected in 1979 for both streamflow and sediment load by the sequential MannKendall test. ${ }^{26,27}$ Simple linear trend analysis indicates that the time series presents a significant downward trend within the confidence level of $95 \%$. Average decreasing rates of $0.04 \times 10^{8} \mathrm{~m}^{3}$ and $0.01 \times 10^{8}$ ton are estimated in streamflow and sediment load, respectively. Average annual streamflow at Huangfu station was $0.82 \times 10^{8} \mathrm{~m}^{3}$ (1980 to 2010), accounting for only $44.8 \%$ of that during 1955 to 1979 . Mean annual sediment load decreased from $0.6 \times 10^{8}$ ton (1955 to 1979 ) to $0.22 \times 10^{8}$ ton (1980 to 2010). Considerable evidence exists that check dams' construction was responsible for the significant reduction in both streamflow and sediment load. ${ }^{8,10} \operatorname{Ran}^{28}$ addressed that streamflow reduced by soil and water conservation measures ranged from 0.14 to $0.53 \times 10^{8} \mathrm{~m}^{3}$ from 1970 to 1996 . Average annual reducing rates for sediment load lay in the range of 5.4 to $23.6 \mathrm{Mt}$. Among these, check dams are the dominant factors retaining discharge and sediment in the watershed. ${ }^{29}$ Furthermore, sediment trapped by the check dams accounted for $>60 \%$ of the total reduced sediment load in the Huangfuchuan catchment.

To better understand the impacts of check dams on streamflow and sediment load, the hydrological time series at Huangfu station were divided into two periods (1955 to 1979 and 1980 to 2010) by the Mann-Kendall test method. A referenced period from 1955 to 1979 was assumed to be the period without intensive human influences on the hydrological process and the changing period was between 1980 and 2010, which was highly affected by human activities. Figures 6(c) and 6(f) show the daily flow duration curves within two different periods. The magnitude of the daily flow generally decreased during the changing period compared with the referenced period. 
Tian et al.: Check dam identification using multisource data and their effects on streamflow...
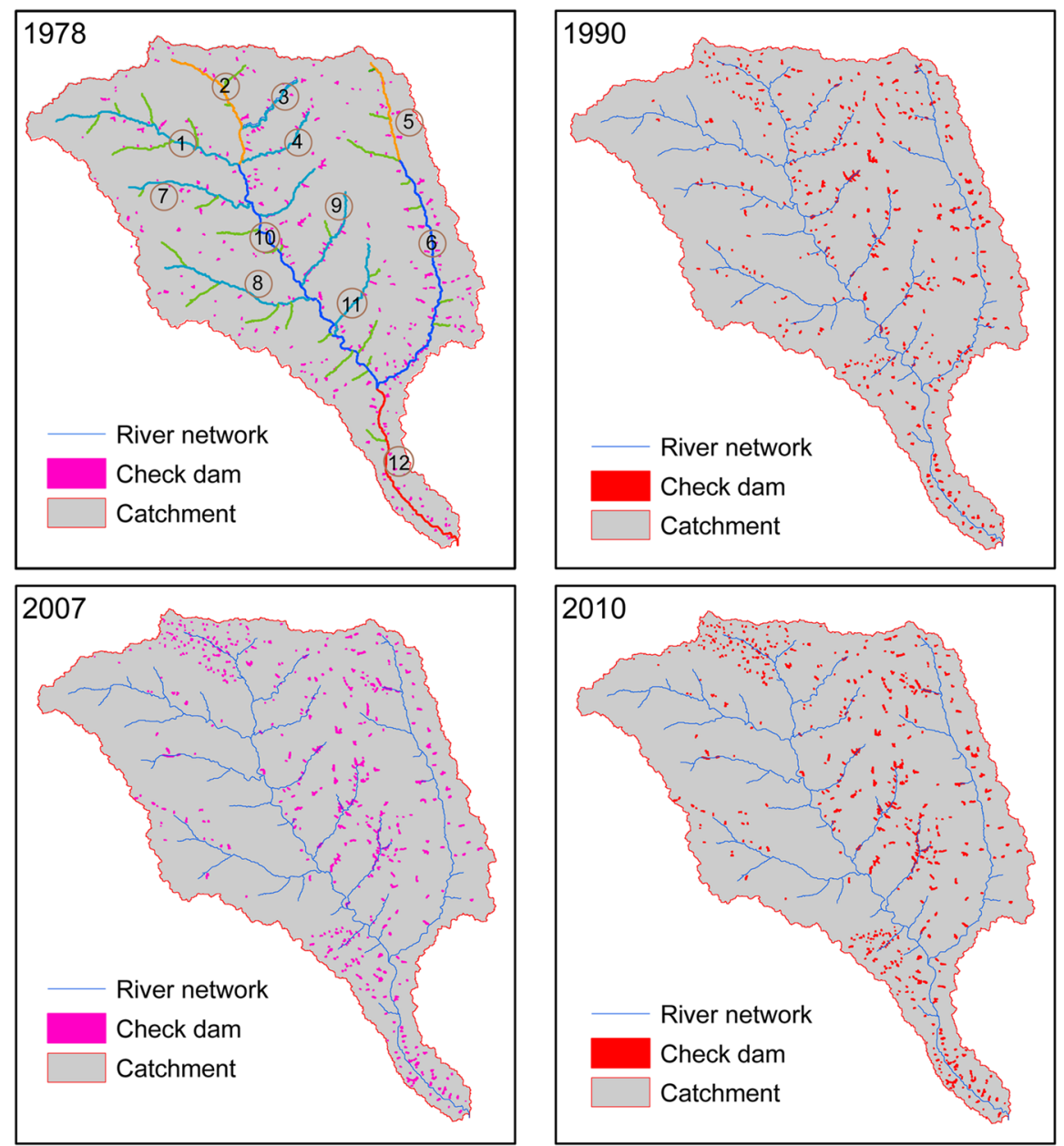

(1) Ganchaban stream (2) Wulan stream (3) Wulasu stream (4) Suji stream (5) Chuanzhang stream (6) Shilichangchuan

(7) Geqiu stream

(8) Hala stream

(9) Hujitu stream

(10) Nalinchuan

(11) Tela stream

(12) Huangfu River

Fig. 5 Historical dynamics of check dams in the Huangfuchuan watershed.
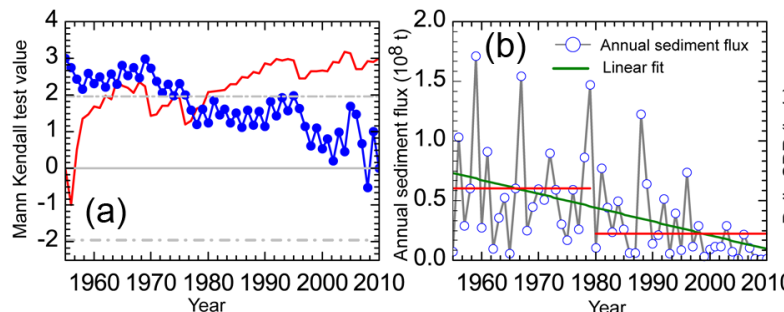

$$
\text { Yea }
$$

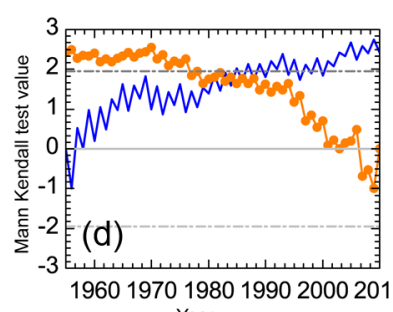

Year

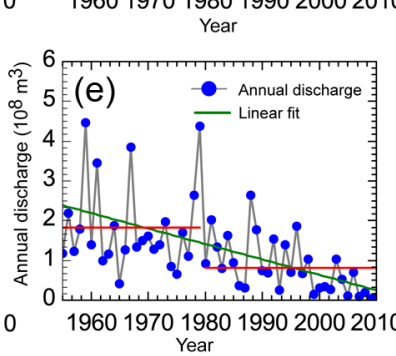

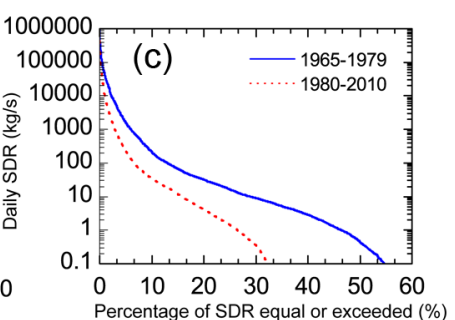

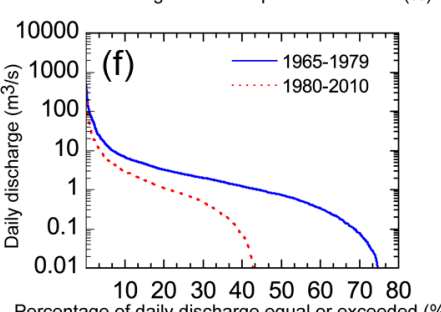

Fig. 6 Changes of discharge and sediment load at Huangfu station from 1955 to 2010. (a, d) MK test for annual sediment load and streamflow, $(b, e)$ linear trends for annual sediment load and streamflow, (c, f) flow duration curve for daily SDR and discharge. 
Tian et al.: Check dam identification using multisource data and their effects on streamflow...

Table 4 Sediment particle sizes during July and August at Huangfu station.

\begin{tabular}{lcccccc}
\hline \hline Periods & $\begin{array}{c}\text { Mean sediment load } \\
\left(10^{4} \text { ton }\right)\end{array}$ & $\begin{array}{c}<0.025 \mathrm{~mm} \\
(\%)\end{array}$ & $\begin{array}{c}0.025 \text { to } 0.05 \mathrm{~mm} \\
(\%)\end{array}$ & $\begin{array}{c}>0.05 \mathrm{~mm} \\
(\%)\end{array}$ & $\begin{array}{c}\text { Median } \\
\text { (Ref. 29) }\end{array}$ & $\begin{array}{c}\text { Mean } \\
\text { (Ref. 29) }\end{array}$ \\
\hline 1966 to 1969 & 2928.16 & 34.95 & 15.56 & 49.48 & 0.059 & 0.152 \\
1970 to 1979 & 2822.06 & 39.50 & 15.05 & 45.45 & 0.059 & 0.132 \\
1980 to 1989 & 1989.64 & 41.61 & 15.17 & 43.22 & 0.051 & 0.127 \\
1990 to 1995 & 1027.19 & 52.67 & 12.48 & 34.85 & 0.030 & 0.104 \\
2005 to 2010 & 598.3 & 57.63 & 16.85 & 25.52 & $\mathbf{0 . 0 2 2}$ & $\mathbf{0 . 0 4 8}$ \\
\hline \hline
\end{tabular}

It can also be clearly seen that zero discharge accounts for much more during the changing period. The daily sediment delivery ratio with 0 values is nearly $60 \%$ within 1955 to 1979 but reduced to $32.6 \%$ during the changing period. There is no discharge measured at Huangfu station during all of 2011. Even a storm in 14th of August with 58.4-mm rainfall did not produce surface flow. ${ }^{30}$ Thus, it can be concluded that numerous soil and water conservation measures, especially, the check dams trapped considerable discharge and sediment in the Huangfuchuan catchment.

\subsection{Sediment Particle Sizes Associated with Check Dam Construction}

In general, hyper-concentrated sediment flow can be trapped in the check dams. In most cases, the check dams consisted of the embankment, spillway, and outlet. Before 1980, most check dams had no spillway or outlet, and all the upstream incoming sediment would be trapped by the dams. In the check dams with spillway, the sediment flow will be filtered. In principle, the coarse grain sediment will deposit rapidly in the water surface area of the dam, and the sediment with fine particle sizes will be flushed away through the spillway. In such cases, most coarse-grain sediment is trapped before the dams.

In the Huangfuchuan catchment, frequently occurring storms mainly concentrated in July and August. Sediment load during these months contributed approximately $70 \%$ of the total. In recent years, zero flow and sediment lasted several months during the dry season. Thus, sediment particle sizes during July and August may represent the effects of check dams on them. As
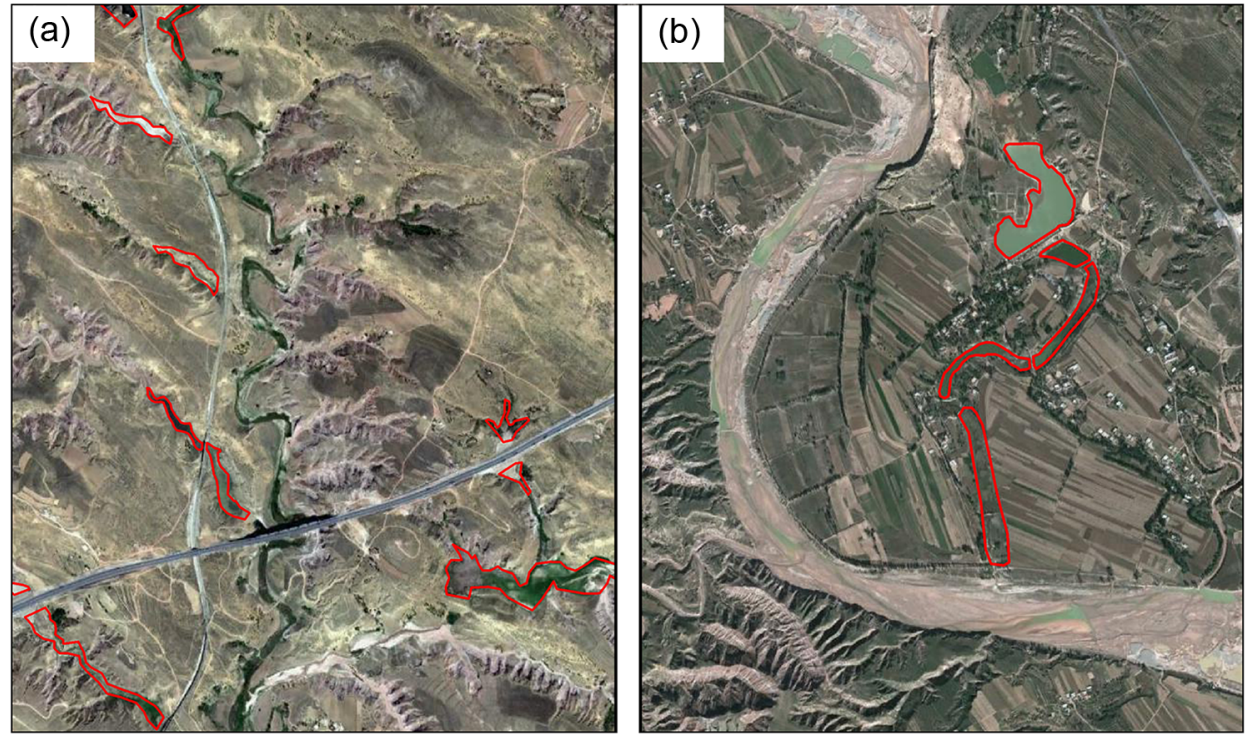

Fig. 7 Potential driving forces for check dam construction. (a) dam construction for highway protection; (b) dam construction for arable land. 
shown in Table 4, observed data at Huangfu hydrological station indicated that mean and median sediment particle diameter illustrated evident decreasing trends, presenting the trapping effects of the check dams. The percentage of sediment particle diameter $<0.025 \mathrm{~mm}$ increased evidently from 1966 to 2010. Both the median and mean value of sediment particle diameter displayed particularly low values during 2005 and 2010 (bold values in Table 4). This is similar to the diameter changes in the middle reaches of the Yellow River. ${ }^{28,29}$

\subsection{Driving Factors of Check Dam Construction}

In most cases, the check dams were constructed for soil erosion control. ${ }^{31}$ However, other objectives such as improving agricultural productivities and building railway or highway become dominant factors. As shown in Fig. 7(a), nearly 10 check dams were constructed for protecting the highway in a $5-\mathrm{km}^{2}$ region of the Huangfuchuan catchment. Road construction has become an important forcing variable for check dam building. Statistics indicate that nearly $20 \%$ of the check dams are connected with the road or used as river bridges. On the other hand, the major aim for building the check dams is to increase agricultural production [Fig. 7(b)]. In general, food production in dam cropland can be 6 to 10 times higher than that in the slope cropland. The average yield is $45,000 \mathrm{~kg} \mathrm{ha}^{-1}$ with some even up to $105,000 \mathrm{~kg} \mathrm{ha}^{-1}{ }^{32}$ Accordingly, dam cropland accounts for about $9 \%$ of the total cropland area in the Loess Plateau, whereas the food production amounts to $20.5 \%$ of the total food production. ${ }^{8}$

\section{Conclusion}

This study identified the spatial distribution, water surface area, and controlled area of the check dams by making use of topographic maps and remote-sensing images in combination with a field survey. An empirical equation was applied to estimate the storage capacity of the check dams associated with the water surface area. Potential effects of the check dams on streamflow and sediment load were additionally addressed. The conclusion of the study can be summarized as follows:

A good correlation between the measured and derived water surface area of the check dams from maps and images was detected. The check dams' information extracted from the remote sensing images is the same as those from Google Earth images, suggesting that the topographic maps and Landsat images can be used for identifying the check dams. Historically, the number of check dams has increased from 390 in 1978 to 567 in 2010, and the dam-controlled area has reached up to $2216.47 \mathrm{~km}^{2}$, accounting for nearly two thirds of the whole catchment. The large numbers of check dams indicate their substantial trapping effects on streamflow and sediment load in the watershed. Filtering effects of check dams have been confirmed due to evident decreasing sediment particle sizes. This study proved that the proposed approach can be applied for extracting check dam information and may provide decision supports for soil and water conservation in the Loess Plateau.

\section{Acknowledgments}

The work was supported by the National Natural Sciences Foundation of China (Grant No. 41201266), the Major Programs of the Chinese Academy of Sciences (KZZDEW-04-03), West Light Foundation of the Chinese Academy of Science (2011ZD03), and the Fundamental Research Funds for the Central Universities (QN2013071). The authors would like to express their great appreciation to the Hydrology Bureau of the Yellow River Water Resources Commission for providing valuable climatic and hydrological data as well as to the reviewers for very valuable comments that greatly improved the quality of the paper.

\section{References}

1. V. M. Castillo et al., "Effectiveness and geomorphological impacts of check dams for soil erosion control in a semiarid Mediterranean catchment: El Cárcavo (Murcia, Spain)," Catena 70(3), 416-427 (2007), http://dx.doi.org/10.1016/j.catena.2006.11.009. 
Tian et al.: Check dam identification using multisource data and their effects on streamflow...

2. C. Boix-Fayos et al., "Effects of check dams, reforestation and land-use changes on river channel morphology: case study of the Rogativa catchment (Murcia, Spain)," Geomorphology 91(1-2), 103-123 (2007), http://dx.doi.org/10.1016/j.geomorph.2007.02.003.

3. L. Zhang, C. X. Shi, and H. Zhang, "Effects of check-dams on sediment storage-release in Chabagou Watershed," Trans. CSAE 26(2), 64-69 (2010) (in Chinese).

4. C. Boix-Fayos et al., "The impact of land use change and check-dams on catchment sediment yield," Hydrol. Process. 22(25), 4922-4935 (2008), http://dx.doi.org/10.1002/hyp .v22:25.

5. X. Z. Xu, H. W. Zhang, and O. Y. Zhang, "Development of check-dam systems in gullies on the Loess Plateau, China," Environ. Sci. Policy 7(2), $79-86$ (2004), http://dx.doi.org/10 .1016/j.envsci.2003.12.002.

6. G. Bombino, V. Tamburino, and S. M. Zimbone, "Assessment of the effects of check-dams on riparian vegetation in the Mediterranean environment: a methodological approach and example application," Ecol. Eng. 27(2), 134-144 (2006), http://dx.doi.org/10.1016/j .ecoleng.2006.01.005.

7. D. C. Ran et al., "Sediment retention by check dams in the Hekouzhen-Longmen Section of the Yellow River," Int. J. Sediment Res. 23(2), 159-166 (2008), http://dx.doi.org/10.1016/ S1001-6279(08)60015-3.

8. Y. F. Wang et al., "Check dam in the Loess Plateau of China: engineering for environmental services and food security," Environ. Sci. Technol. 45(24), 10298-10299 (2011), http://dx .doi.org/10.1021/es2038992.

9. M. Huang et al., "River bed identification for check-dam engineering using SPOT-5 image in the HongShiMao watershed of the Loess Plateau, China," Int. J. Remote Sens. 30(8), 1853-1865 (2009), http://dx.doi.org/10.1080/01431160802508977.

10. Z. Jin et al., "How many check dams do we need to build on the Loess Plateau?," Environ. Sci. Technol. 46(16), 8527-8528 (2012), http://dx.doi.org/10.1021/es302835r.

11. D. Z. Peng et al., "Reservoir storage curve estimation based on remote sensing data," $J$. Hydrol. Eng. 11(2), 165-172 (2006), http://dx.doi.org/10.1061/(ASCE)1084-0699(2006) 11:2(165).

12. W. A. Marcus and M. A. Fonstad, "Optical remote mapping of rivers at sub-meter resolutions and watershed extents," Earth Surf. Proc. Land 33(1), 4-24 (2008), http://dx.doi .org/10.1002/(ISSN)1096-9837.

13. G. X. Wang and S. H. Li, "Application of remote sensing data to extraction of underwater topography of reservoir," J. Hohai Univ. 26(6), 91-94 (1998) (in Chinese).

14. J. Liebe, N. van de Giesen, and M. Andreini, "Estimation of small reservoir storage capacities in a semi-arid environment-a case study in the Upper East Region of Ghana," Phys. Chem. Earth 30(6-7), 448-454 (2005), http://dx.doi.org/10.1016/j.pce .2005.06.011

15. F. O. Annor et al., "Delineation of small reservoirs using radar imagery in a semi-arid environment: a case study in the upper east region of Ghana," Phys. Chem. Earth 34(4-5), 309-315 (2009), http://dx.doi.org/10.1016/j.pce.2008.08.005.

16. J. B. Liu and C. D. Dai, "The application of TM image in reservoir situation monitoring," Chin. Remote Sens. Environ. 11(1), 54-58 (1996) (in Chinese).

17. A. P. Propastin, "Simple model for monitoring Balkhash Lake water levels and Ili River discharges: application of remote sensing," Lake Reservoir: Res. Manage. 13(1), 77-81 (2008), http://dx.doi.org/10.1111/j.1440-1770.2007.00354.x.

18. M. Abedini, M. A. M. Said, and F. Ahmad, "Effectiveness of check dam to control soil erosion in a tropical catchment (The Ulu Kinta Basin)," Catena 97, 63-70 (2012), http://dx.doi.org/10.1016/j.catena.2012.05.003.

19. J. Y. Sui, Y. He, and B. W. Karney, "Flow and high sediment yield from the Huangfuchuan watershed," Int. J. Environ. Sci. Technol. 5(2), 149-160 (2008).

20. USGS, The United States Geological Survey, Earth Explorer database, http://earthexplorer .usgs.gov (28 November 2012).

21. L. S. Ran and X. X. Lu, "Delineation of reservoirs using remote sensing and their storage estimate: an example of the Yellow River basin, China," Hydrol. Process. 26(8), 1215-1229 (2012), http://dx.doi.org/10.1002/hyp.8224. 
Tian et al.: Check dam identification using multisource data and their effects on streamflow...

22. J. R. Jensen, Remote Sensing of the Environment: An Earth Resource Perspective, Prentice Hall, New Jersey (2000).

23. T. Sawunyama, A. Senzanje, and A. Mhizha, "Estimation of small reservoir storage capacities in Limpopo River Basin using geographical information systems (GIS) and remotely sensed surface areas: case of Mzingwane catchment," Phys. Chem. Earth 31(15-16), 935-943 (2006), http://dx.doi.org/10.1016/j.pce.2006.08.008.

24. J. Liebe, "Estimation of water storage capacity and evaporation losses of small reservoirs in the upper east region of Ghana," Diploma Thesis (Univ. of Bonn, 2002).

25. J. Y. Jiao et al., "Silting land and sediment blocking benefit of check dam in hilly and gully region on the Loess Plateau," Trans. CSAE 19(6), 302-306 (2003) (in Chinese).

26. H. B. Mann, "Non-parametric test against trend," Econometrika 13(3), 245-259 (1945).

27. M. G. Kendall, Rank Correlation Methods, Charles Griffin, London (1975).

28. D. C. Ran, "Study on strategies of basin comprehensive harnessing and responses of runoff and sediment to soil and water conservation measures in Huangfuchuan River Basin," Master Thesis, Xi'an University of Technology (2006).

29. S. J. Wang and L. S. Ran, "Analysis of dam effect on sediment yield in the Wudinghe River Basin,” Geog. Res. 27(4), 811-818 (2008) (in Chinese).

30. Yellow River Water Conservancy Commission, Ministry of Water Resources Conservancy, China (2011), Bulletin of the Yellow River, http://www.yellowriver.gov.cn/nishagonggao (18 June 2013).

31. X. M. Fang, Z. H. Wan, and S. F. Kuang, "Mechanism and effect of silt-arrest dams for sediment reduction in the middle Yellow River basin," J. Hydraul. Eng. 29(10), 49-53 (1998) (in Chinese).

32. Ministry of Water Resource of P.R. China, "Programming for check dams in the Loess Plateau," Technical report, pp. 47-48 (2003) (in Chinese).

Biographies and photographs of the authors not available. 